\section{Geological Setting and Age of Australopithecus sediba from Southern Africa}

Paul H. G. M. Dirks, ${ }^{1,2 *}$ ]ob M. Kibii, ${ }^{3}$ Brian F. Kuhn, ${ }^{3}$ Christine Steininger, ${ }^{3,2}$

Steven E. Churchill, ${ }^{4,3}$ Jan D. Kramers, ${ }^{2,5,6}$ Robyn Pickering, ${ }^{7}$ Daniel L. Farber, ${ }^{8,9}$ Anne-Sophie Mériaux, ${ }^{10}$ Andy I. R. Herries, ${ }^{11,12}$ Geoffrey C. P. King, ${ }^{13}$ Lee R. Berger $^{3,2}$

We describe the geological, geochronological, geomorphological, and faunal context of the Malapa site and the fossils of Australopithecus sediba. The hominins occur with a macrofauna assemblage that existed in Africa between 2.36 and 1.50 million years ago (Ma). The fossils are encased in water-laid, clastic sediments that were deposited along the lower parts of what is now a deeply eroded cave system, immediately above a flowstone layer with a U-Pb date of $2.026 \pm 0.021 \mathrm{Ma}$. The flowstone has a reversed paleomagnetic signature and the overlying hominin-bearing sediments are of normal polarity, indicating deposition during the 1.95- to 1.78-Ma Olduvai Subchron. The two hominin specimens were buried together in a single debris flow that lithified soon after deposition in a phreatic environment inaccessible to scavengers.

$\mathrm{T}$ wo hominin fossils assigned to Australopithecus sediba (1) were found in deposits in Malapa cave (Fig. 1). This newly discovered site is one of several Plio-Pleistocene cave deposits in the Cradle of Humankind World Heritage Site (South Africa) that host hominin fossils and associated faunal and archaeological remains, including Sterkfontein, Swartkrans, Kromdraai, and Coopers (2-8). The fossiliferous deposits in these caves formed in broadly similar ways, mostly as debris cone accumulations beneath vertical cave openings (6-11). Clastic sedimentation alternated with periods of erosion (7) or flowstone formation (11), producing unconformities representing time markers between caves. Here we describe the geological, geochronological, geomorphological, and faunal context of the Malapa site and the fossils of $A u$. sediba (1).

Malapa cave formed in stromatolite-rich dolomite of the late Archaean [2.64 to 2.50 billion

\footnotetext{
${ }^{1}$ School of Earth and Environmental Sciences, James Cook University, Townsville, QLD 4811, Australia. ${ }^{2}$ School of Geosciences, University of the Witwatersrand, Johannesburg, Private Bag 3, Wits 2050, South Africa. ${ }^{3}$ Institute for Human Evolution, University of the Witwatersrand, Johannesburg, Private Bag 3, Wits 2050, South Africa. ${ }^{4}$ Department of Evolutionary Anthropology, Box 90383, Duke University, Durham, NC 27708, USA. ${ }^{5}$ Institute of Geological Sciences, University of Bern, Baltzerstrasse 3, 3012 Bern, Switzerland. ${ }^{6}$ Department of Geology, University of Johannesburg, Auckland Park 2006, South Africa. ${ }^{7}$ School of Earth Sciences, University of Melbourne, VIC 3010, Australia. ${ }^{8}$ Center for Accelerator Mass Spectrometry, Lawrence Livermore National Laboratory, Livermore, CA 94550, USA. 'Department of Earth and Planetary Sciences, University of California, Santa Cruz, Santa Cruz, CA 95064, USA. ${ }^{10}$ School of Geography, Politics and Sociology, Newcastle University, Claremont Road, Newcastle upon Tyne NE1 7RU, UK. ${ }^{11}$ UNSW Archaeomagnetism Laboratory, School of Medical Sciences, University of New South Wales, Sydney, NSW 2052, Australia. ${ }^{12}$ Geomagnetism Laboratory, Oliver Lodge, Department of Earth and Ocean Science, University of Liverpool, L69 3BX, UK. ${ }^{13}$ Laboratoire Tectonique, Institut de Physique du Globe Paris, 4 Place Jussieu, 75252 Paris, France.

*To whom correspondence should be addressed. E-mail: paul.dirks@jcu.edu.au
} of the Grootvleispruit, years ago (Ga)] Malmani Subgroup $(12,13)$, which is subdivided into five formations (from base to top: the Oaktree, Monte Christo, Lyttelton, Eccles, and Frisco formations) (13, 14). Malapa cave is located $15 \mathrm{~km}$ north-northeast of Sterkfontein, in the steep-sided valley of the spring-fed Grootvleispruit. It is situated at the north end of a line of north-south-trending caves that are stratigraphically bound to the top $40 \mathrm{~m}$ of the $155-\mathrm{m}$ thick Lyttelton Formation, in layered dolomite that dips $8^{\circ}$ to $13^{\circ}$ to the north-northwest, an angle $2^{\circ}$ to $5^{\circ}$ shallower than the slope of the valley where the caves are exposed (Fig. 1).

Caves near Malapa define a 500-m-long and 100 -m-wide network of interconnected openings along chert-filled fractures (Fig. 1). In the immediate vicinity of Malapa (elevation: $1442 \mathrm{~m}$ above mean sea level), erosion remnants of cave deposits form shallow depressions. Caves farther upslope are progressively deeper and preserve interconnected subterranean caverns that reach a vertical depth of 25 to $30 \mathrm{~m}$. The cave system closes above an elevation of $\sim 1490 \mathrm{~m}$, directly below the sheared upper contact of the Lyttelton formation (Fig. 1). These trends, combined with valley slope and bedding orientation, suggest that Malapa lies near the base of an originally $>30-\mathrm{m}$ deep, strata-bound and fracture-controlled cave system eroded by valley incision.

Malapa cave formed at the intersection of a north-northeast and a north-northwest fracture, with hominin remains occurring in a 3.5-m-deep excavation ( $3.3 \mathrm{~m}$ by $4.4 \mathrm{~m}$ in size) centered on the north-northwest fracture. Minor limestone mining took place at Malapa in the early 20th century, exposing in situ hominin material. The cave deposits comprise five distinct sedimentary facies called, from base to top, A to E. Facies A-B occur below a central flowstone sheet (Fig. 2 and fig. S1). The fossils of $A u$. sediba (1) are in facies $\mathrm{D}$, with additional hominin remains in facies $\mathrm{E}$ (Fig. 2)

Facies A consists of dark-colored, moderately sorted, coarse-grained clastic sediment, with abun-

Fig. 1. Location of the Malapa site in the valley showing the principal geological controls on cave formation. Malapa is positioned along a complex fracture system in the most deeply eroded parts of a 500 -m-long cave system as illustrated by section $\mathrm{A}-\mathrm{B}$.

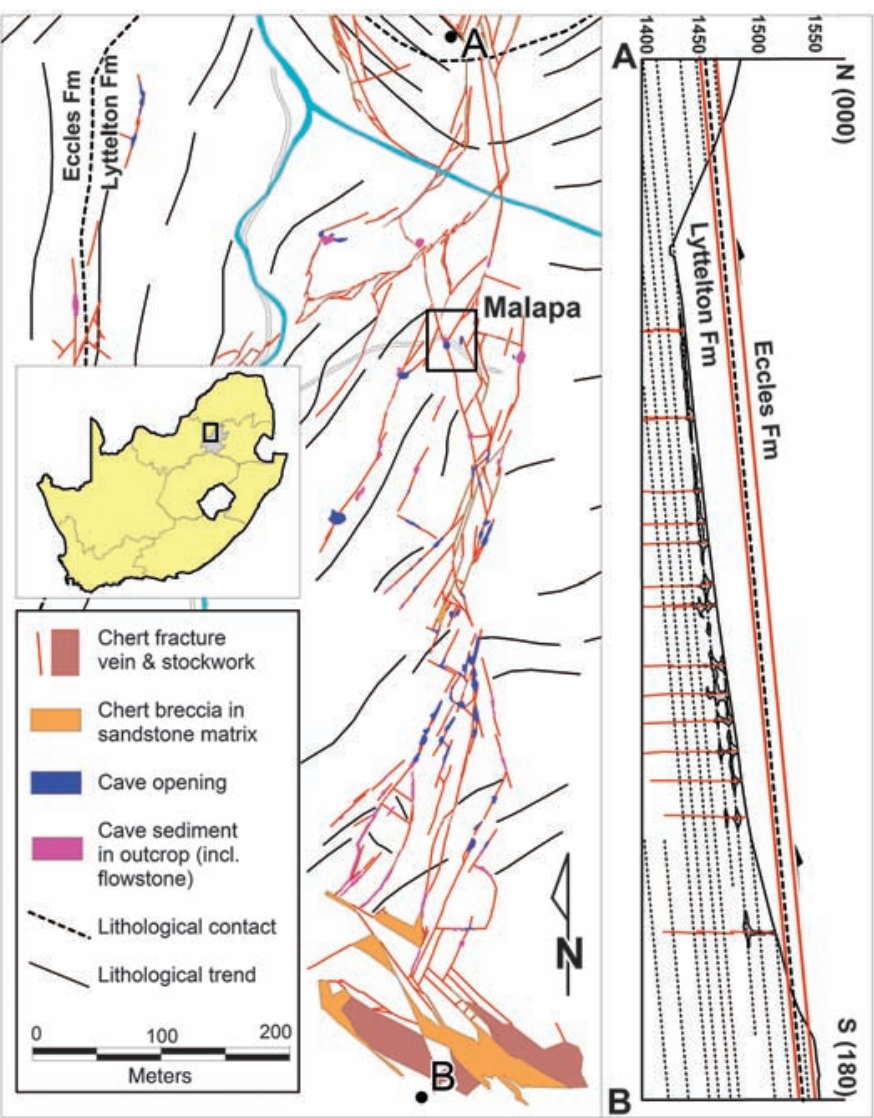


dant rounded grains ( 0.5 to $6 \mathrm{~mm})$ of chert, quartz, dolomite, iron oxide-coated grains or ooids, bone fragments and peloids, and little feldspar and mica schist. The openly packed framework grains are embedded in blocky sparite. Bedding is defined by normal and inverse grading, and a weak preferred orientation of rock and bone fragments. The coarsest-grained parts of facies $\mathrm{A}$ occur toward the center of the unit defining a shallow central channel.

Facies B consists of peloidal grainstone alternating with clastic sandstone. The grainstone contains $>50 \%$ rounded peloids and lesser amounts of bone fragments and clastic grains (mostly quartz), many iron oxide-coated, to form an open framework cemented with blocky sparite. Fenestrae with sparry calcite are common along horizontal bedding planes. Peloids ( 0.4 to $1 \mathrm{~mm}$ ) consist of fine-grained $(0.02$ to $0.10 \mathrm{~mm})$ angular quartz grains in a micaceous mud and sparite matrix. Sandstone rich in bone fragments and rounded iron oxide-coated grains forms layers preserving grading (coarsening and fining upward) and grain imbrication. Small stalagmite bosses growing on a grainstone substrate, and isolated limestone blocks $(<40 \mathrm{~cm})$, are incorporated in facies B.

After deposition, facies A and B were eroded and covered by a flowstone carapace that dips moderately to the north-northeast, indicating north-directed water flow along the cave axis. The flowstone contains intercalations of fossilbearing, detrital sandstone. A milky quartz vein surrounded by an alteration halo of iron oxide and clay intruded facies $\mathrm{A}-\mathrm{B}$, but does not appear to intrude the flowstone (Fig. 2).

Facies $\mathrm{C}$ is identical to the peloidal grainstone units in facies B. It is preserved as a 5- to $30-\mathrm{cm}$ thick erosion remnant that drapes over the flowstone in the northwest corner of the pit (Fig. 2). Subrounded fragments of quartz, limestone, and shale, many iron oxide-coated, as well as bone fragments, occur toward the top of the layer, and fenestrae are common.

Facies D overlies flowstone in the center and east of the pit and sits unconformably on facies $\mathrm{C}$ in the west. This massive, up to 1.5-m-thick, lightcolored unit contains abundant, well-preserved macro- and micromammal fossils, including the remains of two skeletons of $A u$. sediba (1) and articulated remains of Equus sp. (Fig. 2). The poorly sorted, coarse-grained sandstone is cemented by blocky sparite, which displays isopachous (radial outward) overgrowths in larger pore spaces. Framework grains are mostly 0.5 to $2.5 \mathrm{~mm}$ in size and consist of quartz, chert, dolomite, peloids, and, less commonly, iron oxide-coated grains, ooids, shale, and feldspar (microcline). Rounding varies from well-rounded ooids to angular veinquartz crystals. Angular limestone blocks $(<50 \mathrm{~cm})$ and flowstone fragments $(<5 \mathrm{~cm})$ occur throughout facies D. Peloids are common, but peloidal boundaries are diffuse, and groups of peloids are fused in irregular patches. The hominin skeletons are in close spatial association, separated by no more than $40 \mathrm{~cm}$ vertically (Fig. 2). The recovered remains of the juvenile occur in close association (1) toward the top of facies $\mathrm{D}$, and the partly articulated remains of the adult (1) occur near the base.

Facies E consists of calcareous sandstone, similar to facies D, but darker colored and finer grained, with a higher degree of sorting and rounding, and preserving 4- to $15-\mathrm{cm}$-scale horizontal layering. The basal layer of facies $\mathrm{E}$ consists of well-sorted, coarse-grained sandstone dominated by 0.6 - to $1.5-\mathrm{mm}$-large iron oxide-coated chert and quartz grains and aggregates of peloids. The layer preserves northwest-dipping laminations, indicating directional water flow. Horizontal layering in facies $\mathrm{E}$ is defined by grain-size variations (coarsening and fining upward), mud partings, thin $(<1 \mathrm{~mm})$ flowstone drapes, and orientated bone fragments. Fossil bone is abundant, but less well preserved than bone in facies $\mathrm{D}$, with solution damage and partial fragmentation suggesting exposure to standing or flowing water before final burial and cementation (15).

The rocks of facies A-E were water-laid with all sandstone units displaying loose packing of framework grains indicating little postdepositional compaction (16). Abundant fenestrae in facies B and $\mathrm{C}$ reflect trapped gas possibly formed from the decay of organic matter $(16,17)$. The abundant peloids are interpreted as fecal remains $(16,17)$ or soil micropeds $(11,18)$. Coalescence of peloids in facies $\mathrm{D}$ and $\mathrm{E}$ reflects mechanical

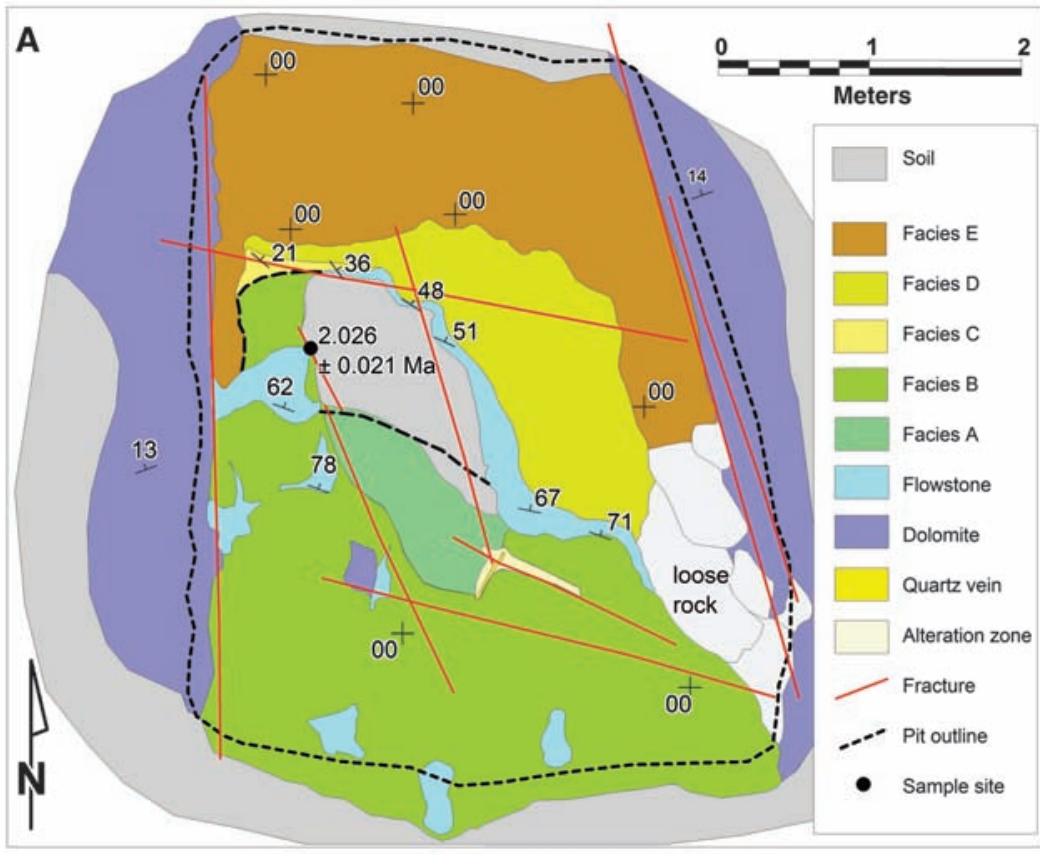

Fig. 2. Detailed geological map of the Malapa pit showing the distribution of the principal rock facies $(\mathbf{A})$ and their occurrence in the north face $(\mathbf{B})$ and south face $(\mathbf{C})$ of the pit together with the position of fossils of $A$. sediba, Equus sp., and Dinofelis sp. The sample position for dating the flowstone is indicated.

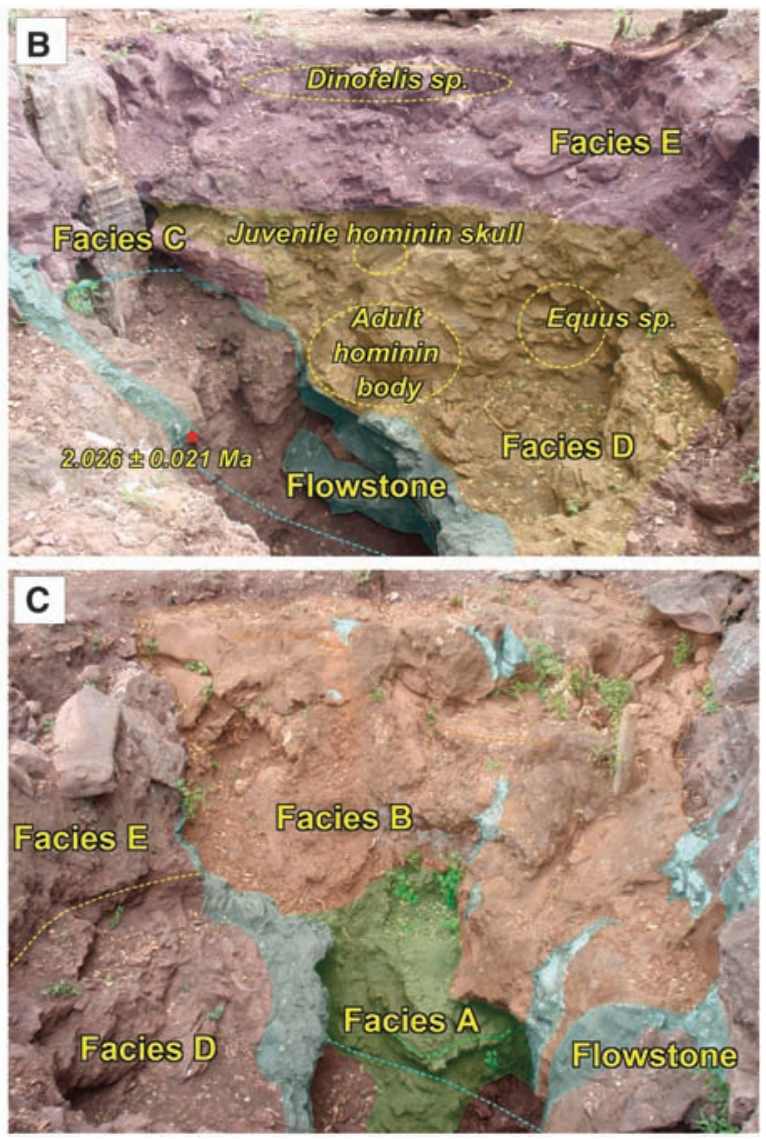


reworking of unconsolidated peloids deposited in a water-logged environment. The homogeneous sandstone of facies D contains allochtonous material (chert, shale and feldspar grains, bone fragments) mixed with cave-derived sediment and coarse blocks, suggesting deposition as a single debris flow that carried partially articulated (i.e., only partially decomposed) hominins with it. The superb preservation and state of articulation of fossil material (1) indicate rapid deposition, limited transport distance, and laminar flow conditions consistent with debris flows $(17,19)$. The presence of isopachous sparite indicates that cementation occurred soon after deposition in a phreatic environment (10). After the debris flow, the cave filled with horizontally layered clastic deposits (facies E) dominated by autochtonous sediment with sedimentary structures indicating north-directed water flow that weakened and strengthened from time to time, carrying with it bone fragments and partially articulated faunal remains. Absence of carnivore damage in the fossil assemblage indicates that scavengers had no access to the cave.

Table 1. Nonhominin faunal material recovered from Malapa with estimates of minimum numbers of individuals (MNI) and number of identified specimens (NISP).

\begin{tabular}{|c|c|c|c|c|c|}
\hline Order & Family & Tribe & Genus and species & MNI & NISP \\
\hline \multirow[t]{7}{*}{ Carnivora } & Felidae & & Dinofelis sp. & 1 & 2 \\
\hline & & & Megantereon whitei & 1 & 1 \\
\hline & & & Felis silvestris & 1 & 1 \\
\hline & Hyaenidae & & Parahyaena brunnea & 2 & 8 \\
\hline & Canidae & & Lycaon sp. & 1 & 1 \\
\hline & Herpestidae & & Atilax mesotes* & 1 & 1 \\
\hline & & & Mungos sp. & 1 & 1 \\
\hline Perissodactyla & Equidae & & Equus sp. & 1 & 1 \\
\hline \multirow[t]{6}{*}{ Artiodactyla } & Suidae & & Suidae Indet. & 1 & 1 \\
\hline & Bovidae & Neotragini & Oreotragus sp. & 1 & 1 \\
\hline & & Alcelaphini & Megalotragus sp. & 1 & 1 \\
\hline & & & Large-sized alcelaphine & 1 & 1 \\
\hline & & Tragelaphini & Tragelaphus cf. scriptus & 1 & 1 \\
\hline & & & Tragelaphus cf. strepsiceros & 1 & 1 \\
\hline Lagomorpha & Leporidae & & Lepus sp. & 1 & 3 \\
\hline Total & & & & 16 & 25 \\
\hline
\end{tabular}

${ }^{*}$ Considered by some to be Herpestes mesotes.

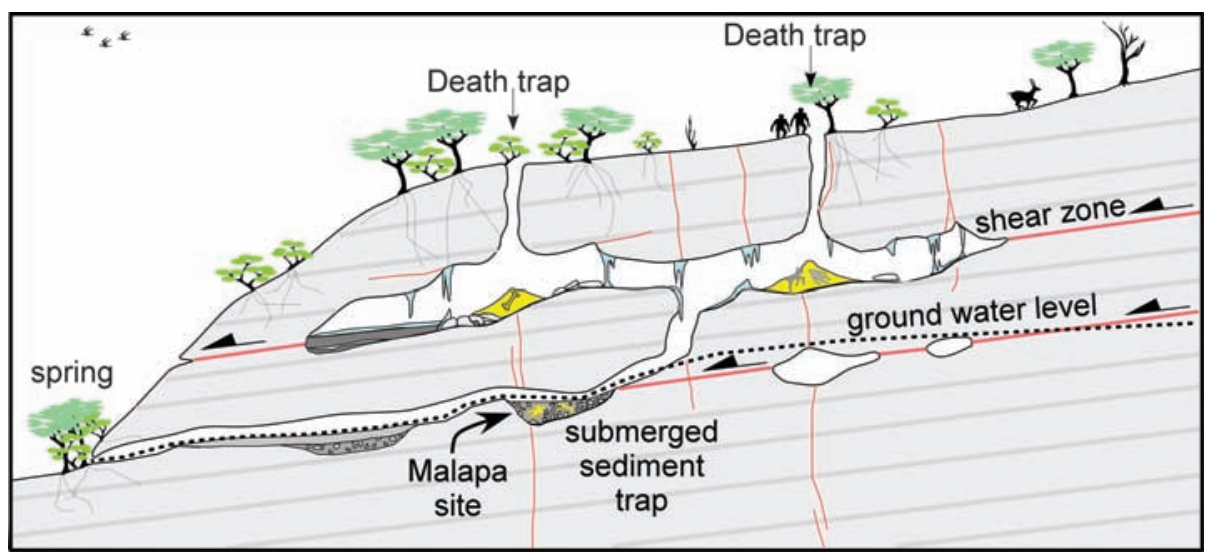

Fig. 3. Cartoon illustrating how two hominins might have become trapped and buried in alluvial sediments at the bottom of a Pliocene cave. age limit for the hominin remains (table $\mathrm{S} 1$ and fig. S3).

To further constrain the age of deposition of the fossils, we took samples for paleomagnetic analysis from across the flowstone layer and the overlying sedimentary facies (SOM Text S2, table S3, and figs. S1, S4, and S5). The flowstone mainly preserves reverse polarity, but near its base, a normal polarity excursion occurs that is interpreted as the Huckleberry Ridge Subchron at $2.06 \pm 0.04 \mathrm{Ma}(25)$. The sediments of facies $\mathrm{C}$, $\mathrm{D}$, and $\mathrm{E}$ above the flowstone record normal polarity that is interpreted as the beginning of the 1.95- to 1.78-Ma Olduvai Subchron (26).

To constrain the level of erosion and original depth of the cave system, we collected samples for cosmogenic ${ }^{10} \mathrm{Be}$ analysis from two sites (SOM Text S3, table S4, and fig. S6) to bracket the minimum and maximum erosion rates Malapa experienced: (i) the plateau $650 \mathrm{~m}$ south and $82 \mathrm{~m}$ above Malapa (TNHL08) equated to the African Erosion Surface (5) that is thought to have experienced low erosion rates $(<10 \mathrm{~m})$ over the past tens of millions of years, and (ii) the gently northwest-dipping bedrock channel of the Grootvleispruit, $3400 \mathrm{~m}$ west-northwest and $85 \mathrm{~m}$ below Malapa (LH08). Samples from TNHL08 give consistent values for the long-term erosion rate of the surface of $\sim 3$ to $5 \mathrm{~m}$ per million years (My) with a mean of $3.6 \pm 1.1 \mathrm{~m} / \mathrm{My}$ (table S5). These rates are more than an order of magnitude higher than are common in ancient relic landscapes (27-29) and indicate that over the past $\sim 2$ million years, at least $\sim 8 \mathrm{~m}$ of overburden was removed from Malapa. To constrain the downcutting rate of the river into shale overlying the Malmani Subgroup, and thus the rate of valley formation, we collected bedrock samples from LH08 from a chert layer forming a dip slope and the stream channel (SOM Text S3 and fig. S7). A linear fit to data collected from $\sim 1$ to $6 \mathrm{~m}$ above the active channel spans a time frame of $10^{5}$ years and yields a river incision rate of $53 \pm 9 \mathrm{~m} / \mathrm{My}$ (fig. S8). This suggests that erosion rates at Malapa are significantly greater than those measured on the plateau, indicating that Malapa cave was tens of meters deep when the Hominin fossils were deposited.

As a taphonomic hypothesis, we suggest that at the time of burial of the hominins, the complex cave system near Malapa had opened along deep vertical shafts that operated as death traps to animals on the surface (Fig. 3). In addition to being inconspicuous drops into which animals accidentally wandered, the cave openings may have been loci of animal activity, enhancing their operation as natural traps. Animals might have been attracted to the smell of water coming from the shaft, and carnivores might have been attracted to the smell of decomposing bodies. These factors could have operated to accumulate a diverse assemblage of carcasses in the chamber below, away from carnivore activity. The sediments imply that subsequent high-volume water inflow, perhaps the result of a large storm, caused a 
debris flow that carried the still partially articulated bodies deeper into the cave, to deposit them along a subterranean stream (Fig. 3).

\section{References and Notes}

1. L. R. Berger et al., Science 328, 195 (2010).

2. R. Broom, J. T. Robinson, Nature 164, 322 (1949).

3. A. R. Hughes, P. V. Tobias, Nature 265, 310 (1977).

4. R. Clarke, S. Afr. J. Sci. 94, 460 (1998)

5. T. C. Partridge, in The Cenozoic of Southern Africa, T. C. Partridge, R. R. Maud, Eds. (Oxford Univ. Press, New York, 2000), pp. 100-125.

6. T. C. Partridge, D. E. Granger, M. W. Caffee, R. J. Clarke, Science 300, 607 (2003).

7. C. K. Brain, in Swartkrans: A Cave's Chronicle of Early Man, C. K. Brain, Ed. (Monogr. 8, Transvaal Museum, Pretoria, ed. 2, 2004)

8. D. J. de Ruiter et al., J. Hum. Evol. 56, 497 (2009)

9. T. C. Partridge, Nature 275, 282 (1978).

10. C. K. Brain, in Palaeoclimate and Evolution, with Emphasis on Human Origins, E. S. Vrba, Ed. (New Haven, 1995), pp. 385-424.

11. R. Pickering et al., J. Hum. Evol. 53, 602 (2007).

12. D. McB. Martin, C. W. Clendennin, B. Krapez, N. J. McNaughton, J. Geol. Soc. London 155, 311 (1998).

13. P. G. Eriksson et al., in The Geology of South Africa, M. R. Johnson, C. R. Anhaeusser, R. J. Thomas, Eds. (Geological Society of South Africa, Johannesburg, 2006), pp. 237-260.

14. K. A. Eriksson, J. F. Truswell, Trans. Geol. Soc. S. Afr. 77, 211 (1974).
15. C. K. Brain, The Hunters or the Hunted? An Introduction to African Cave Taphonomy (Univ. of Chicago Press, Chicago, 1981).

16. H. Blatt et al., Petrology: Igneous, Sedimentary and Metamorphic (Freeman, New York, ed. 3, 2006).

17. M. E. Tucker, Sedimentary Petrology (Blackwell, Oxford, ed. 2, 1991).

18. G. J. Retallack, Soils of the Past: An Introduction to Palaeopedeology (Harper Collins, London, 1990).

19. P. Coussot, M. Meunier, Earth Sci. Rev. 40, 209 (1996).

20. L. R. Berger, R. Lacruz, D. J. De Ruiter, Am. J. Phys. Anthropol. 119, 192 (2002).

21. J. P. Brugal, H. Roche, M. Kibunjia, C. R. Palevol. 2, 675 (2003).

22. F. H. Brown, I. McDougall, I. Davies, R. Maier, in Ancestors: The Hard Evidence, E. Delson, Ed. (Liss, New York, 1985), pp. 82-90.

23. M. E. Lewis, L. Werdelin, in Hominin Environments in the East African Pliocene: An Assessment of the Faunal Evidence, R. Bobe, Z. Alemseged, A. K. Behrensmeyer, Eds. (Springer, Netherlands, 2007), pp. 77-105.

24. J. D. Woodhead et al., Quat. Geochronol. 1, 208 (2006).

25. M. A. Lanphere, D. E. Champion, R. L. Christiansen, G. A. Izett, GSA Bull. 114, 559 (2002)

26. J. G. Ogg, A. G. Smith, in A Geologic Time Scale 2004, F. Gradstein, ]. G. Ogg, A. G. Smith, Eds. (Cambridge Univ. Press, Cambridge, UK, 2004), pp. 63-86.

27. K. Nishiizumi, M. W. Caffee, R. C. Finkel, G. Brimhall, T. Mote, Earth Planet. Sci. Lett. 237, 499 (2005).

28. S. R. Hall, D. L. Farber, L. Audin, R. C. Finkel, A. S. Meriaux, Tectonophysics 459, 186 (2008).
29. A. Matmon et al., Geol. Soc. Am. Bull. 121, 688 (2009).

30. We thank the South African Heritage Resource Agency for allowing work on the Malapa site; the Nash family for granting access to the Malapa site and continued support; the Palaeontological Scientific Trust (PAST), the Institute for Human Evolution, University of the Witwatersrand and the School of Geosciences, University of the Witwatersrand, for funding; and the University of the Witwatersrand's Schools of Geosciences and Anatomical Sciences and the Bernard Price Institute for Palaeontology for support and facilities. Further support was provided by AfricaArray (P.H.G.M.D.), the France-SA !Khure Africa project (G.C.P.K., D.L.F., A.-S.M.), and LLNL GEO-CAMS and the US-NSF EAR-0345895 (D.L.F.). R.P. is supported by a Swiss National Science Foundation Post-Doctoral Grant and gratefully acknowledges J. Woodhead, A. Grieg, and the team at Melbourne University. A.I.R.H. was funded through a UNSW Faculty of Medicine research grant and ARC Discovery Grant DP0877603 and acknowledges the support of the Liverpool University Geomagnetism Laboratory staff. Contributions to mapping and sample preparation by G. Charlesworth and Z. Jinnah are kindly acknowledged.

Supporting Online Material

www.sciencemag.org/cgi/content/full/328/5975/205/DC1

SOM Text S1 to S3

Figs. S1 to S8

Tables S1 to S4

References

19 November 2009; accepted 26 February 2010

$10.1126 /$ science. 1184950

\section{Why Copy Others? Insights from the Social Learning Strategies Tournament}

\author{
L. Rendell, ${ }^{1 *}$ R. Boyd ${ }^{2}$ D. Cownden, ${ }^{3}$ M. Enquist, ${ }^{4,5}$ K. Eriksson, ${ }^{5,6}$ M. W. Feldman, ${ }^{7}$ L. Fogarty, $^{1}$ \\ S. Ghirlanda, ${ }^{5,8}$ T. Lillicrap, ${ }^{9}$ K. N. Laland ${ }^{1 *}$
}

Social learning (learning through observation or interaction with other individuals) is widespread in nature and is central to the remarkable success of humanity, yet it remains unclear why copying is profitable and how to copy most effectively. To address these questions, we organized a computer tournament in which entrants submitted strategies specifying how to use social learning and its asocial alternative (for example, trial-and-error learning) to acquire adaptive behavior in a complex environment. Most current theory predicts the emergence of mixed strategies that rely on some combination of the two types of learning. In the tournament, however, strategies that relied heavily on social learning were found to be remarkably successful, even when asocial information was no more costly than social information. Social learning proved advantageous because individuals frequently demonstrated the highest-payoff behavior in their repertoire, inadvertently filtering information for copiers. The winning strategy (discountmachine) relied nearly exclusively on social learning and weighted information according to the time since acquisition.

$\mathrm{H}$ uman culture is widely thought to underlie the extraordinary demographic success of our species, manifest in virtually every terrestrial habitat $(1,2)$. Cultural processes facilitate the spread of adaptive knowledge, accumulated over generations, allowing individuals to acquire vital life skills. One of the foundations of culture is social learning, learning influenced by observation or interaction with other individuals (3), which occurs widely in various forms across the animal kingdom (4). Yet it remains something of a mystery why individuals profit by copying others and how best to do this.

At first sight, social learning appears advantageous because it allows individuals to avoid the costs, in terms of effort and risk, of trial-anderror learning. However, social learning can also cost time and effort, and theoretical work reveals that it can be error-prone, leading individuals to acquire inappropriate or outdated information in nonuniform and changing environments (5-11). Current theory suggests that to avoid these errors individuals should be selective in when and how they use social learning, so as to balance its advantages against the risks inherent in its indiscriminate use (9). Accordingly, natural selection is expected to have favored social learning strategies, psychological mechanisms that specify when individuals copy and from whom they learn $(12,13)$
These issues lie at the interface of multiple academic fields, spanning the sciences, social sciences and humanities, from artificial intelligence to zoology $(5,14-18)$. Formal theoretical analyses [e.g., $(2,5-9,11-13,19)]$ and experimental studies $(20,21)$ have explored a small number of plausible learning strategies. Although insightful, this work has focused on simple rules that can be studied with analytical methods and can only explore a tiny subset of strategies. For a more authoritative understanding of when to acquire information from others and how best to do so, the relative merits of a large number of alternative social learning strategies must be assessed. To address this, we organized a computer tournament in which strategies competed in a complex and changing simulation environment. $€ 10,000$ was offered as first prize. The organization of similar tournaments by Robert Axelrod in the 1980s proved an extremely effective means for

${ }^{1}$ Centre for Social Learning and Cognitive Evolution, School of Biology, University of St. Andrews, Queen's Terrace, St. Andrews, Fife KY16 9TS, UK. ²Department of Anthropology, University of California, Los Angeles, CA 90095, USA ${ }^{3}$ Department of Mathematics and Statistics, Queen's University, Jeffery Hall, University Avenue, Kingston, Ontario K7L 3N6, Canada. ${ }^{4}$ Department of Zoology, Stockholm University, 11691 Stockholm, Sweden. ${ }^{5}$ Centre for the Study of Cultural Evolution, Stockholm University, 11691 Stockholm, Sweden. ${ }^{6}$ School of Education, Culture, and Communication, Mälardalen University, 72123 Västerås, Sweden. ${ }^{7}$ Department of Biological Sciences, Stanford University, Stanford, CA 94305, USA ${ }^{8}$ Department of Psychology, University of Bologna, 40127 Bologna, Italy. ${ }^{9}$ Centre for Neuroscience Studies, Queen's University, 18 Stuart Street, Kingston, Ontario K7L 3N6, Canada.

*To whom correspondence should be addressed. E-mail: ler4@st-andrews.ac.uk (L.R.); knl1@st-andrews.ac.uk (K.N.L.) 